\title{
Empirical and Statistical Study of Elicitation Complications
}

\author{
Author 1Sidra Arshad \\ sidra_arshad143@yahoo.com \\ Author 2 Hafiza Tahira Fazal \\ tahiramalik1230@gmail.com \\ Author 3 Tahir Nawaz \\ nwfpaup@yahoo.com
}

\section{Abstract}

The performance of Requirement Engineering is like framework for software development process. All-inclusive software has four mainstays of requirement engineering processes i.e. Functional and non-functional requirements, design, implementation and testing build the complete software fortification on top of the mainstays. Requirement engineers have to face numerous challenges to develop successful and impressive software. Requirements Engineering (RE) leads software development process. Different constraints and needs of users are explored as well as hitches in previous system are depicted. The scope of this study is to exemplify the difficulties faced by users in the utmost maiden phase of RE Requirements Elicitation and a framework is presented as well. A survey was conducted in different campuses of Universities in Pakistan for this purpose. Questionnaire was distributed among project development students of various disciplines to gather and highlighted the problems during Requirements Elicitation.

Finally the predictive statistical software SPSS was used to input the collected data for more precise calculations, the results of which are discussed in section 3.

\section{KEYWORDS: Requirement Elicitation; Requirement Engineering; Users' Problems; Empirical study; Agile INTRODUCTION}

Software development process reconnoitering software requirements are vital. If the requirements are not plainly recognized, severe inaccuracies may cause software failure or immense financial damage. Thus, it is significant to get the customers involved all over the development process and to timely ask about their requirements. Requirements Engineering (RE) has five phases viz. Requirements Elicitation; Requirements Analysis and Negotiation; Documentation; Requirements Verification and Validation and Requirements Management [1]. However, the emphasis of this paper is on the "Requirements Elicitation" phase.

Requirement elicitation phase examines the complications in current system. However, errors in requirement phase are not recognized during software development. Rather they remain obscured until system becomes completely functional and participant's needs are not met [2].

The minor errors in elicitation phase can cause serious problems and failures in later stages of the application development process. The failure may become the cause of system crash or major financial loss. Different researches concluded that problem of requirements is major issue at different levels of software development. When causes of failure were enquired, executive managers identified poor requirements as foremost of the problems. Others are lack of user involvement $(13 \%)$, requirements incompleteness $(12 \%)$, changing requirements $(11 \%)$, unrealistic expectations $(6 \%)$ and unclear objectives (5\%). On the European side, a recent survey of over 3,800 organizations in 17 countries similarly established that most of the apparent software problems are in the area of requirements specification $(>50 \%)$ and requirements management (50\%) [3]

In this paper the elicitation process will be examined and reviewed through an empirical analysis as well as in section 2 some elicitation methodologies will also be reviewed. In section 4 will describe the results of the empirical analysis, in section 5 a frame work will be defined for the problems that are faced during elicitation and section 6 will be the conclusion of the paper.

\section{LITERATURE REVIEW}

Requirement Elicitation is the phase in which requirements are gathered. The term "Elicit" basic mean is "To Produce" and so different types of requirements regarding the project are produced during this phase.

Information collected during this phase has to be interpreted, analyzed, demonstrated and certified before starting implementation.

The two major types of methodologies for eliciting requirements are: Traditional Methodologies and Agile Methodologies, some of which are discussed below:

\section{Traditional Techniques}

These techniques include a wide-range collection of standard data gathering techniques. The main traditional techniques are questionnaires, surveys, interviews, ethnography and focus groups. These methodologies do not have users' involvement during the development process unlike agile methodologies.

\section{Agile Methodologies}

Agile Methodologies are iterative and contain users' involvement during the development process through continuous contact with them. Typically, a person among the users is selected as a representative who is a computer literate and therefore can communicate in a better way with the development team. There are different types of agile methodologies; Extreme Programming (XP), scrum, DSDM, FDD, ASD and crystal methodology. Scrum is alike to a part of XP but Scrum 
is not as comprehensive as XP and it just shelters the area of planning game of XP only. However, scrum and XP can be used concurrently in several development projects [4]

Planning Game: The main part of agile methodologies is Planning Game i.e. Customers involvement during project development as customers fully participate in the development of the system by having regular meetings with the development team. The development process depends upon short term periodic releases to make the requirements unambiguous and easily understandable. Planning game is based on the understanding of users and programmers. Moreover, acceptance tests are applied to check that the whole team is working properly. These tests are normally created by the users to check the working of the system. There is not any fixed number of tests but depends upon the completion of the story but each test should be cleared in every iterations. All the tests are programmed and computerized. Finally the report is submitted to the development team.

Traceability in Agile Development: Due to traceability in agile methods, all the material can be gathered, well- structured and easy to explore. It ensures that the development team can find a simple technique to make a link among different objects. But the team should be skilled enough to trace the information and the decisions that were made during the whole development process. [5]

Traceability depends on the life span and size of the project. The development team should properly communicate with the customer to get the information about the life span of the project, if the life of project is one year then there is no need of traceability but if the project has to be implemented for a long period of time then traceability and documentation should be added. [6]

\section{MANIPULATED RESULTS OF SURVEY}

The survey was conducted using questionnaires. Questionnaires were distributed among different students, doing final projects. After data collection, statistical software SSPS was used to manipulate the collected data. Bar graphs are designed using SSPS and finally crosstab test is applied to the more engrossed question to get more precise results. The students were asked to tell about their experience of final project. The first precise question asked from students was about the techniques which they followed for requirement elicitation. The resulted graph is as under

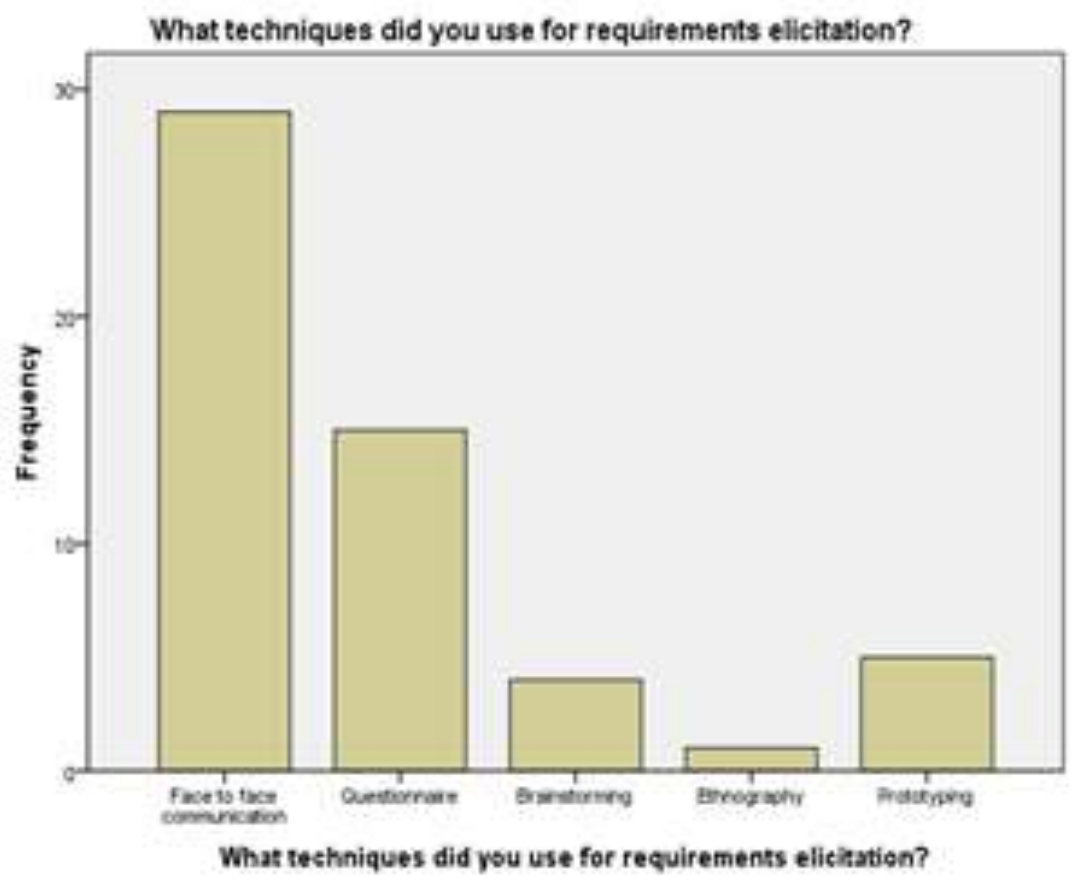

Fig: 1 Technique

It is clear in Fig 1 that the most commonly followed technique is "Face to face Communication" and the least followed technique is Ethnography. So it is clear from the graph that face to face communication is mostly preferred technique for requirements elicitation. The next most important question regarding the survey was about the problems that are faced during requirements elicitation. 


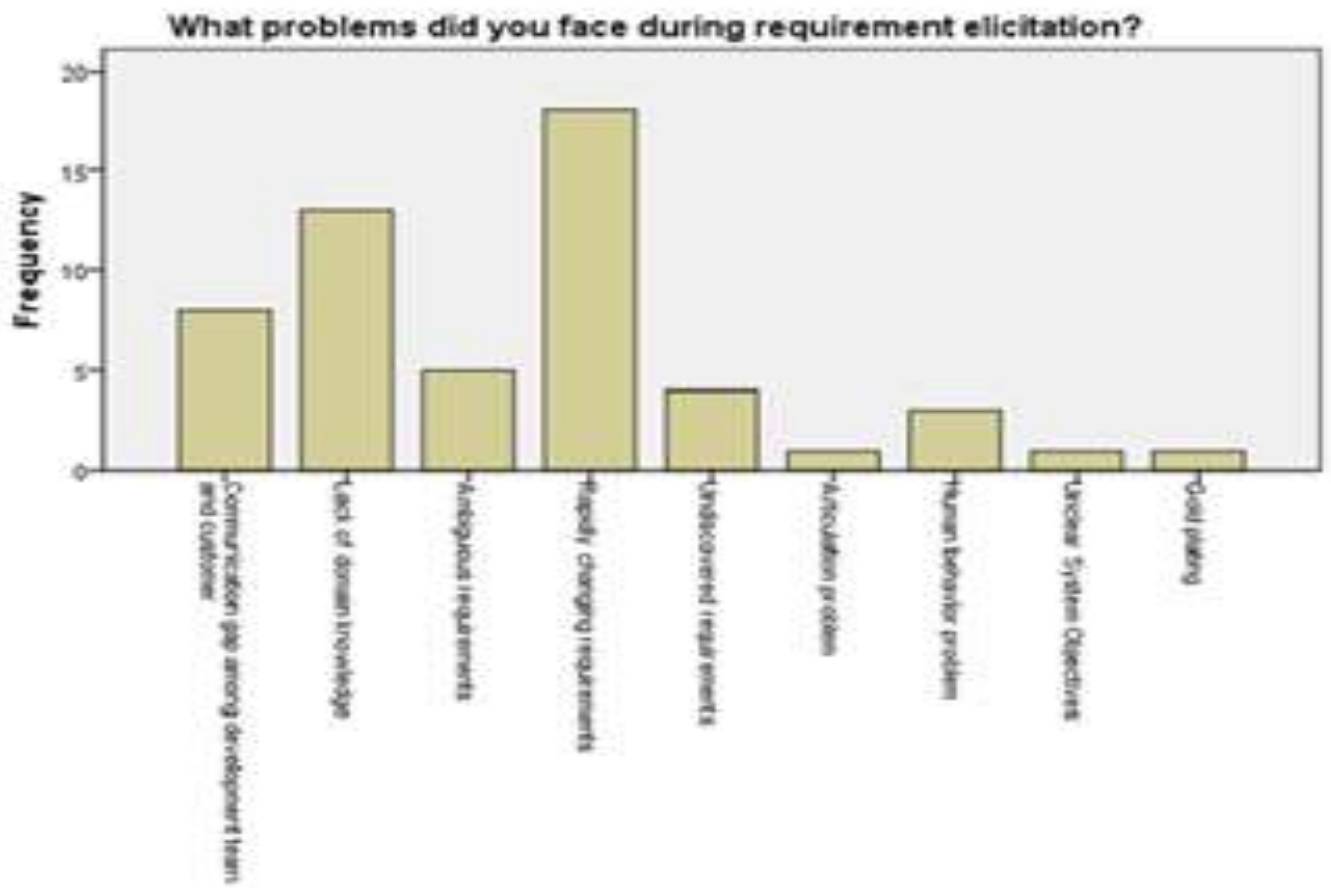

Fig: 2 Problems

The result shows that the problem most faced during elicitation was rapidly changing requirements while articulation and gold plating are the least faced problems. The next question was about the requirements about which students were interested to gather data for their project.

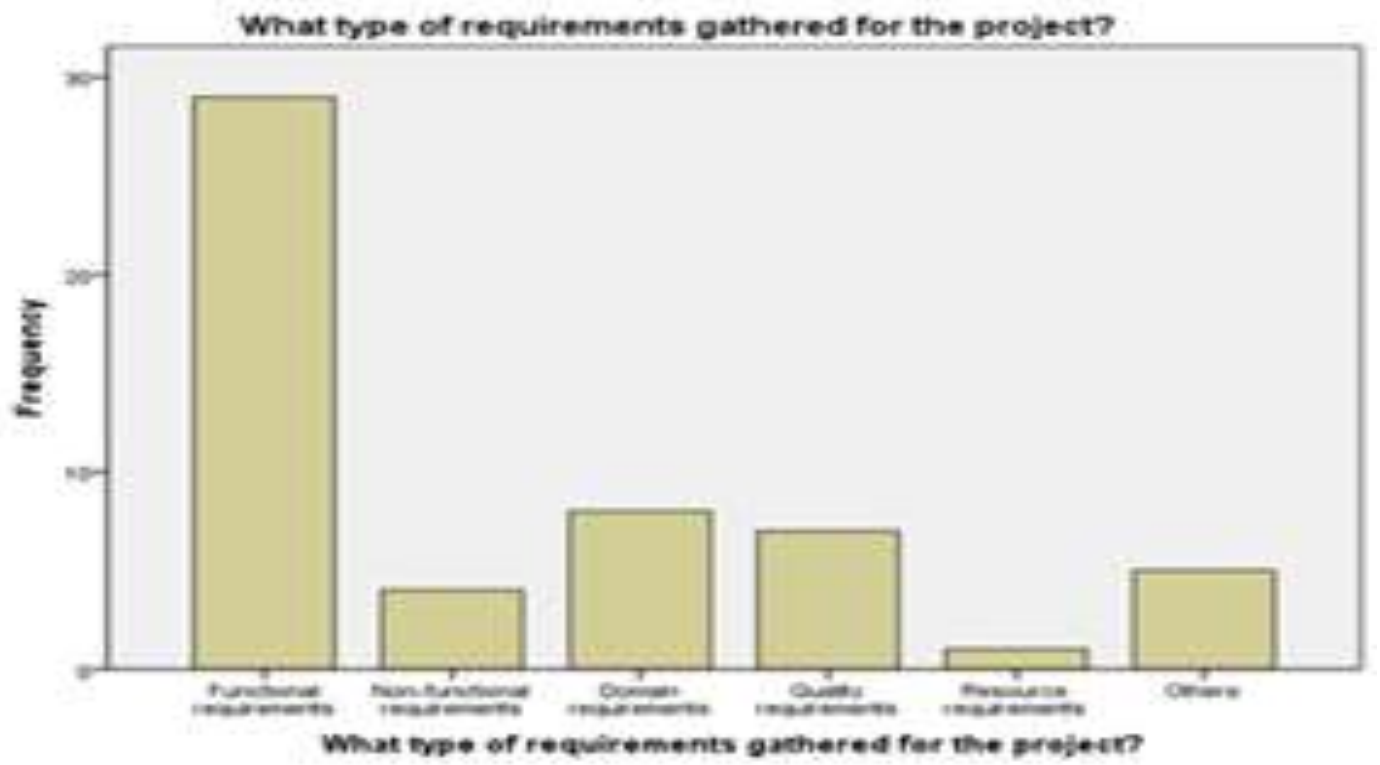

Fig: 3 Requirements

Different options were enlisted in the questionnaire but according to the results of Fig: 3 , the requirements about which the data is gathered are functional requirement while resource requirements were not of much focus. So the result shows that the gathered requirements for developed projects or for the projects that are under development mostly based on the functional requirements while all other requirements do not gain much attention by the developers.

In traditional methodologies, there are different models for project development that were enlisted in questionnaire to gather data that which traditional model is mostly followed during the development phase. 


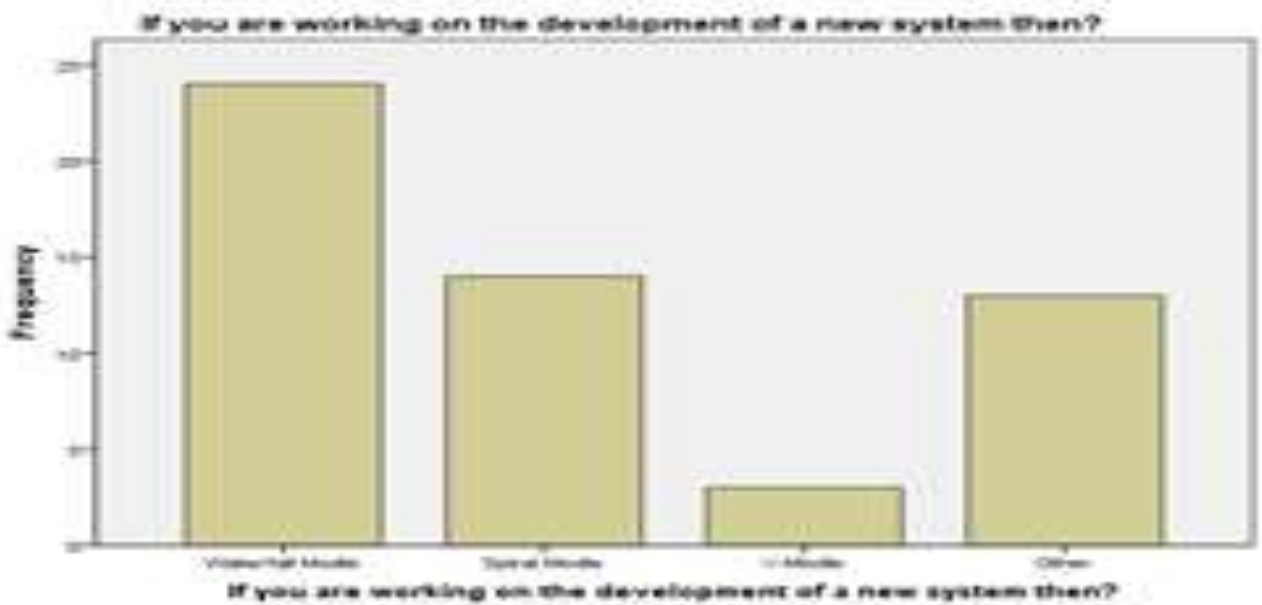

Fig: 4 Traditional Models

Above figure shows the result that the most commonly followed model is water fall model and V-Model could not gather much attention of the developers. It is asked that what type of methodology is mostly preferred. The result clearly shows that agile methodologies are mostly preferred by the developers. Following is the figure that shows the result regarding preferred methodologies

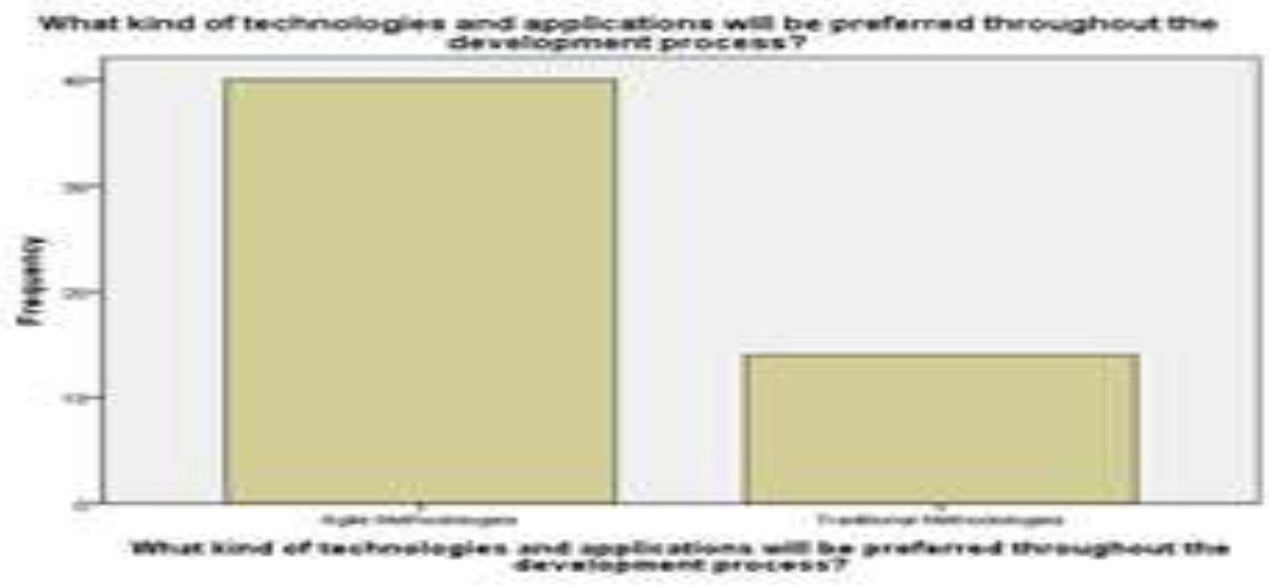

Fig: 5 Preferred Methodologies

It is clear from fig: 5 that developers preferred agile methodology but during the practical implementation traditional methodologies are followed due to lack of knowledge about practical implementation of agile.

After drawing charts of the gathered data, cross tabulation test was applied on some questions for more precise prediction. Following tables are the result of cross tabulation of two questions i.e. what techniques did you use for requirements elicitation?

${ }^{*}$ What problems did you face during requirement elicitation?

Table: 1

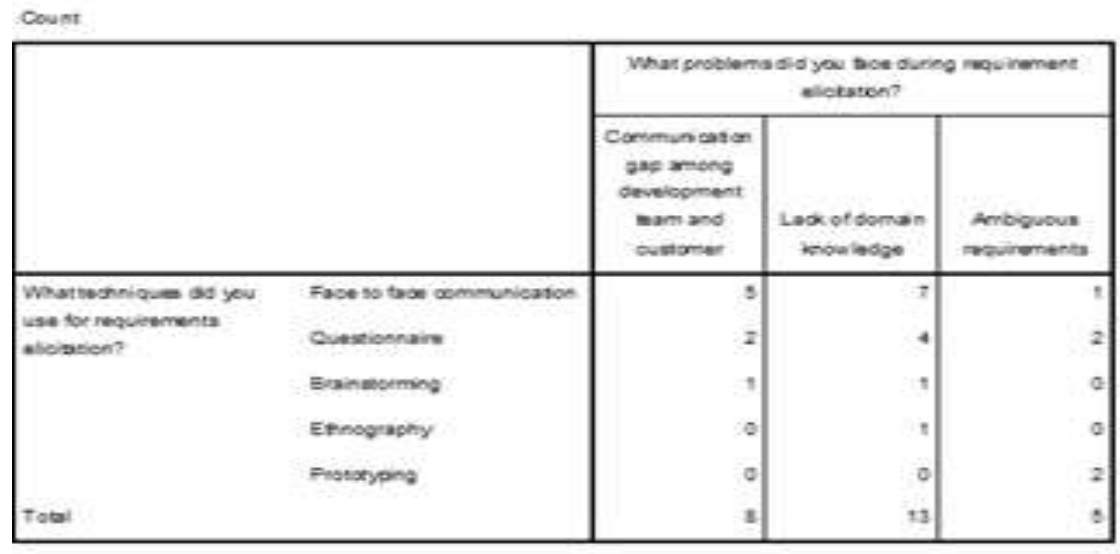


Table: 2

\begin{tabular}{|c|c|c|c|c|}
\hline & & \multicolumn{3}{|c|}{ 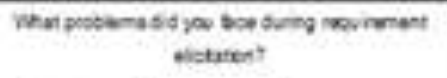 } \\
\hline & & 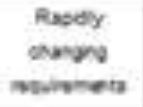 & 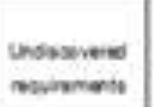 & $\begin{array}{l}\text { Arovinen } \\
\text { nosolem }\end{array}$ \\
\hline 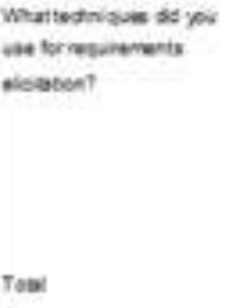 & 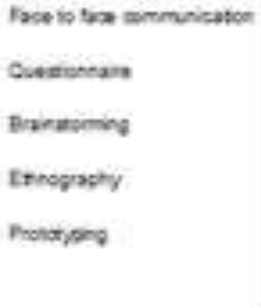 & $\begin{array}{l}\mathrm{t} \\
\mathrm{s} \\
0 \\
0 \\
0 \\
0\end{array}$ & $\begin{array}{l}0 \\
1 \\
1 \\
0 \\
= \\
4\end{array}$ & $\begin{array}{l}0 \\
0 \\
0 \\
0 \\
1\end{array}$ \\
\hline
\end{tabular}

Table: 3

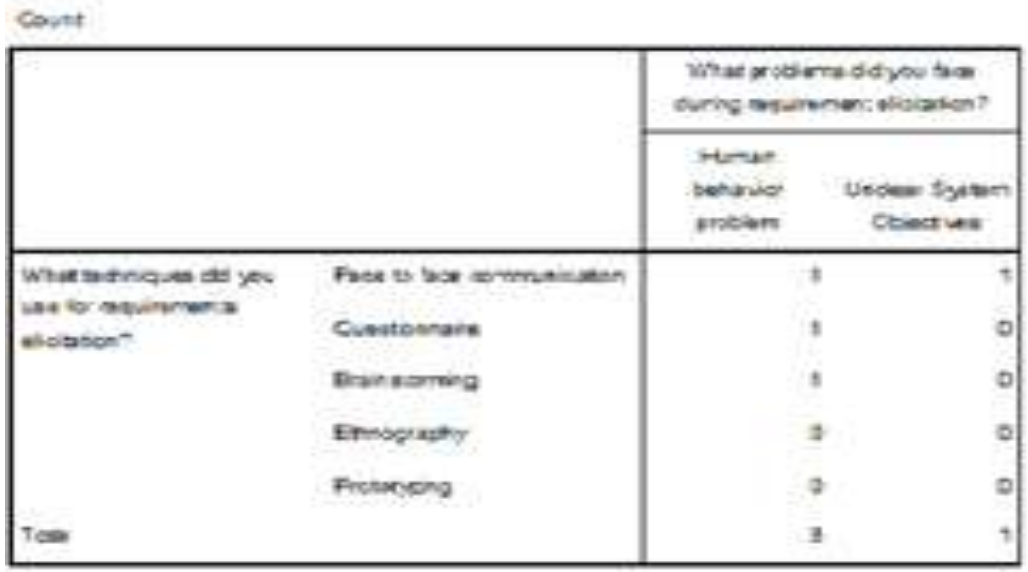

Table: 4

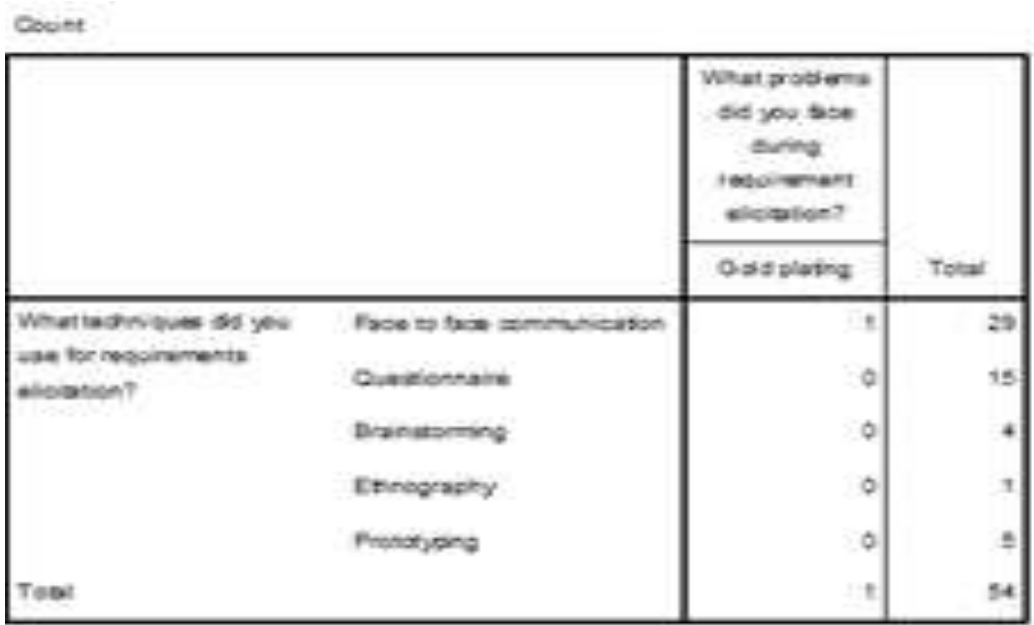

After collecting the data from a small group of student's i.e around 54, shown the valuable results in Table 1, 2, 3 and 4 ; if face to face communication is followed then 5 will be having communication gap, 7 will be face lack of domain knowledge, 1 will be facing ambiguous requirements, 13 will be facing rapidly changing requirements, 1,1 will be facing human behavior problem and unclear objectives and 1 will be facing gold plating. Now if next technique is observed i.e. Questionnaire; 2 will be facing the problem of communication gap, 4 will be having lack of domain knowledge, 2 will facing ambiguous requirements, 5 will be facing rapidly changing requirements, 1 , 1 will be facing the problem due to undiscovered problems and human behavior problems.

Similarly, according to the results of brainstorming 1 will be facing communication gap and 1 will be facing the problem of domain knowledge, 1 will be facing human behavior and 1 will be facing undiscovered requirement. In ethnography just 1 will be facing the problem that is of lack of domain knowledge. In the technique of prototyping, 2 will be facing the problem 
of ambiguous requirements, 2 will be facing the problem of undiscovered requirements and 1 will be facing the problem of articulation problem.

If the results of table 1 to 4 are summarized, the most commonly followed techniques are face to face communication and questionnaire and the main focus of the problem faced in these techniques is rapidly changing requirements. The next questions which are cross tabulated are as follows

*What type of requirements gathered for the project?

*What kind of technologies and applications will be preferred throughout the development process? The results of which are as follows

Table: 5

\begin{tabular}{|c|c|c|c|c|}
\hline & & \multicolumn{2}{|c|}{$\begin{array}{c}\text { What kind of technologies and } \\
\text { applications will be preferred } \\
\text { throughout the development } \\
\text { process? }\end{array}$} & \multirow[b]{2}{*}{ Total } \\
\hline & & $\begin{array}{c}\text { Agile } \\
\text { Methodologies }\end{array}$ & $\begin{array}{c}\text { Traditional } \\
\text { Methodologies }\end{array}$ & \\
\hline $\begin{array}{l}\text { What type of requirements } \\
\text { gathered for the project? }\end{array}$ & $\begin{array}{l}\text { Functional requirements } \\
\text { Non-functional requirements } \\
\text { Domain requirements } \\
\text { Quality requirements } \\
\text { Resource requirements } \\
\text { Others }\end{array}$ & $\begin{array}{l}22 \\
2 \\
6 \\
6 \\
1 \\
3\end{array}$ & \begin{tabular}{l|}
7 \\
2 \\
2 \\
2 \\
1 \\
0 \\
2
\end{tabular} & \\
\hline Total & & 40 & 14 & \\
\hline
\end{tabular}

According to the result of the above table the more preferred methodology is agile and the more preferred requirements to be gathered following agile methodologies are functional requirements and the least preferred requirements are resource requirements while the preferred requirements to be gathered in traditional methodologies are functional requirements while resource requirements obtain null value.

\section{CONCLUSION}

A survey was conducted among the students of final year project to analyze the problems of requirements elicitation during software development. Questionnaire was used to gather data. SPSS is used to manipulate the gathered data, bar charts and cross tabulation test is manipulated through it. Results showed that students practically use traditional methodologies but prefer agile methodologies however due to lack of knowledge in practical implementation of agile they cannot use it in their final project. Moreover the requirements which are mostly collected for project development are functional requirements of the project while resource requirements are negligible during the development process.

The major problems that are faced are rapidly changing requirements and communication gap. These problems can be solved using agile methodologies because the main theme of agile methodologies is to keep the involvement of user throughout the life of project development as well as regular meetings among development team and users are encouraged unlike traditional methodologies that are mostly based on documentation.

\section{FUTURE WORK}

Analysis of survey results evidently shows that agile methodologies are not practically implemented, and knowledge of agile emphasis the practical implementation.

\section{ACKNOWLEDGEMENTS}

Appreciated efforts of all students participated in this research study, provided significant information and their time in data collection, which enable us to share very important features of this research and concluded valuable asset to improve the requirements elicitation and to provide new areas for future work. Furthermore, we are also thankful to our family members those who help us and encourage us in hard days of result compilation.

\section{REFERENCES}

[1] Husnain, M., M. Waseem., S.A.K. Ghayyur, (2009). An Interrogative Review of Requirement Engineering Frameworks. International Journal of Reviews in Computing Pakistan. 2 (1). ISSN: 2076-3328

[2] B.Thomas. "Meeting the challenges of Requirement Engineering." News at Software Engineering Institute. 2009. Website: http://www.sei.cmu.edu/library/abstracts/newsatsei/spotlightmar99pdf.cfm. Access date: January 2016.

[3] European Software Institute 1996. "European User Survey Analysis", Report USV_EUR 2.1, ESPITI Project, January 1996. 
[4] Asghar, S. and M. Umar. 2010. Requirement Engineering Challenges in Development of Software Applications and Selection of Customer-off-the-Shelf (COTS) Components. International Journal Software Engineering. (Kuala Lumpur, Malaysia). 1(2): 32-50. ISSN: 2180-1320.

[5] Poppendieck, Mary and Tom Poppendieck, Lean Software Development: An Agile Toolkit. Addison Wesley Professional, USA. 2003. ISBN:0321150783

[6] Veerapaneni Esther Jyothi and K. Nageswara Rao. 2011. Effective Implementation of Agile Practices-- Ingenious and Organized Theoretical Framework. International Journal of Advanced Computer Science and Applications, 2(3). http://dx.doi.org/10.14569/IJACSA.2011.020308 